\title{
Change of quasilattice constant during amorphous-to-quasicrystalline phase transformation in Zr65A17.5Ni10Cu7.5Ag10 metallic glass
}

\author{
Jiang, Jianzhong; Rasmussen, A.R.; Jensen, C.H.; Lin, Y.; Hansen, P.L.
}

\section{Published in:}

Applied Physics Letters

Link to article, DOI:

$10.1063 / 1.1463207$

Publication date:

2002

Document Version

Publisher's PDF, also known as Version of record

Link back to DTU Orbit

Citation (APA):

Jiang, J., Rasmussen, A. R., Jensen, C. H., Lin, Y., \& Hansen, P. L. (2002). Change of quasilattice constant during amorphous-to-quasicrystalline phase transformation in Zr65Al7.5Ni10Cu7.5Ag10 metallic glass. Applied Physics Letters, 80(12), 2090-2092. https://doi.org/10.1063/1.1463207

\section{General rights}

Copyright and moral rights for the publications made accessible in the public portal are retained by the authors and/or other copyright owners and it is a condition of accessing publications that users recognise and abide by the legal requirements associated with these rights.

- Users may download and print one copy of any publication from the public portal for the purpose of private study or research.

- You may not further distribute the material or use it for any profit-making activity or commercial gain

- You may freely distribute the URL identifying the publication in the public portal 


\title{
Change of quasilattice constant during amorphous-to-quasicrystalline phase transformation in $\mathrm{Zr}_{65} \mathrm{Al}_{7.5} \mathrm{Ni}_{10} \mathrm{Cu}_{7.5} \mathrm{Ag}_{10}$ metallic glass
}

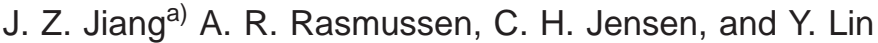 \\ Department of Physics, Building 307, Technical University of Denmark, DK-2800 Kgs. Lyngby, Denmark \\ P. L. Hansen \\ Haldor Topsфe A/S, Nymøllevej 55, DK-2800 Kgs. Lyngby, Denmark
}

(Received 26 September 2001; accepted for publication 28 January 2002)

\begin{abstract}
The amorphous-to-quasicrystalline phase transformation in a $\mathrm{Zr}_{65} \mathrm{Al}_{7.5} \mathrm{Ni}_{10} \mathrm{Cu}_{7.5} \mathrm{Ag}_{10}$ metallic glass has been investigated by monitoring the quasilattice constant and the composition of quasicrystalline particles in the samples annealed in vacuum at $663 \mathrm{~K}$ for various times. It is found that the quasilattice constant decreases with annealing time and saturates after 90 min while the zirconium and silver contents in quasicrystalline particles differ from those in the remaining amorphous matrix. The results provide evidence that the amorphous-to-quasicrystalline phase transformation in the $\mathrm{Zr}_{65} \mathrm{Al}_{7.5} \mathrm{Ni}_{10} \mathrm{Cu}_{7.5} \mathrm{Ag}_{10}$ metallic glass is a nonpolymorphous reaction. (C) 2002 American Institute of Physics. [DOI: 10.1063/1.1463207]
\end{abstract}

In 1996, Koster and his co-workers ${ }^{1}$ reported the formation of icosahedral quasicrystals from $\mathrm{Zr}-\mathrm{Al}-\mathrm{Cu}-\mathrm{Ni}$ metallic glasses. Since then, the mechanism of the amorphous-toquasicrystalline phase transformation in Zr-based metallic glasses has been intensively studied and still remains debated. ${ }^{2-17}$ For a $\mathrm{Zr}_{65} \mathrm{Al}_{7.5} \mathrm{Ni}_{10} \mathrm{Cu}_{7.5} \mathrm{Ag}_{10}$ metallic glass, Inoue and his co-workers, ${ }^{10}$ studied the kinetics of the transformation by performing isothermal differential scanning calorimeter (DSC) measurements. Using the JohnsonMehl-Avrami equation, they estimated the Avrami exponent to be close to 4 . In addition, they performed nanobeam energy dispersive $\mathrm{x}$-ray (EDX) analyses on quasicrystalline particles and the remaining amorphous phase in the $\mathrm{Zr}_{65} \mathrm{Al}_{7.5} \mathrm{Ni}_{10} \mathrm{Cu}_{7.5} \mathrm{Ag}_{10}$ metallic glass annealed at $705 \mathrm{~K}$ for $60 \mathrm{~s}$ and found no difference in composition between the quasicrystalline and the remaining amorphous phases. They suggested a polymorphous transformation for the amorphous-to-quasicrystalline transformation in the $\mathrm{Zr}_{65} \mathrm{Al}_{7.5} \mathrm{Ni}_{10} \mathrm{Cu}_{7.5} \mathrm{Ag}_{10}$ alloy. Lee et al., ${ }^{11}$ reported that formation of quasicrystalline phase in a similar alloy $\mathrm{Zr}_{65} \mathrm{Al}_{7.5} \mathrm{Ni}_{10} \mathrm{Cu}_{12.5} \mathrm{Ag}_{5}$ is not entirely polymorphic in nature and may involve partitioning of the solute on the basis of their isothermal DSC measurements. Furthermore, Jiang et al. ${ }^{14}$ performed in situ isothermal kinetic $x$-ray diffraction (XRD) measurements using synchrotron radiation for the $\mathrm{Zr}_{65} \mathrm{Al}_{7.5} \mathrm{Ni}_{10} \mathrm{Cu}_{7.5} \mathrm{Ag}_{10}$ metallic glass. The results of the pressure effect on crystallization temperature and the relative volume fraction versus time at four temperatures suggested that atomic mobility is important for the time-dependent nucleation of quasicrystals from the metallic glass. The Avrami exponent was found to be close to one. In this work, we report the changes of quasilattice constant and composition of the quasicrystalline phase during amorphous-to-quasicrystalline phase transformation in the $\mathrm{Zr}_{65} \mathrm{Al}_{7.5} \mathrm{Ni}_{10} \mathrm{Cu}_{7.5} \mathrm{Ag}_{10}$ metallic glass.

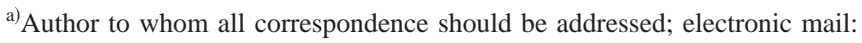
jiang@fysik.dtu.dk
}

A ribbon sample of the $\mathrm{Zr}_{65} \mathrm{Al}_{7.5} \mathrm{Ni}_{10} \mathrm{Cu}_{7.5} \mathrm{Ag}_{10}$ metallic glass with a cross section of $0.03 \mathrm{~mm} \times 1 \mathrm{~mm}$ was prepared by the melt-spinning technique from a master alloy ingot prepared by arc melting in an Ar atmosphere. The amorphous nature of the as-quenched ribbon was confirmed by XRD and transmission electron microscopy (TEM). Thermal analysis was performed by a DSC at a heating rate of $5 \mathrm{~K} / \mathrm{min}$ under a flow of purified argon. The alloy exhibits an endothermic event characteristic of the glass transition, followed by two characteristic exothermic events indicating a two-stage phase transformation process, i.e., amorphous-to-quasicrystalline and quasicrystalline-to-intermetallic compounds. ${ }^{14}$ It was found that the glass transition temperature $T_{g}$, estimated as the onset temperature of the glass transition event, is $628 \mathrm{~K}$, the onset temperatures and the exothermic heats of the first and second crystallization events, $T_{x 1}=672 \mathrm{~K}, T_{x 2}=730 \mathrm{~K}$ and $34.1 \mathrm{~J} / \mathrm{g}, 40.4 \mathrm{~J} / \mathrm{g}$, respectively, and $\Delta T=T_{x 1}-T_{g}$

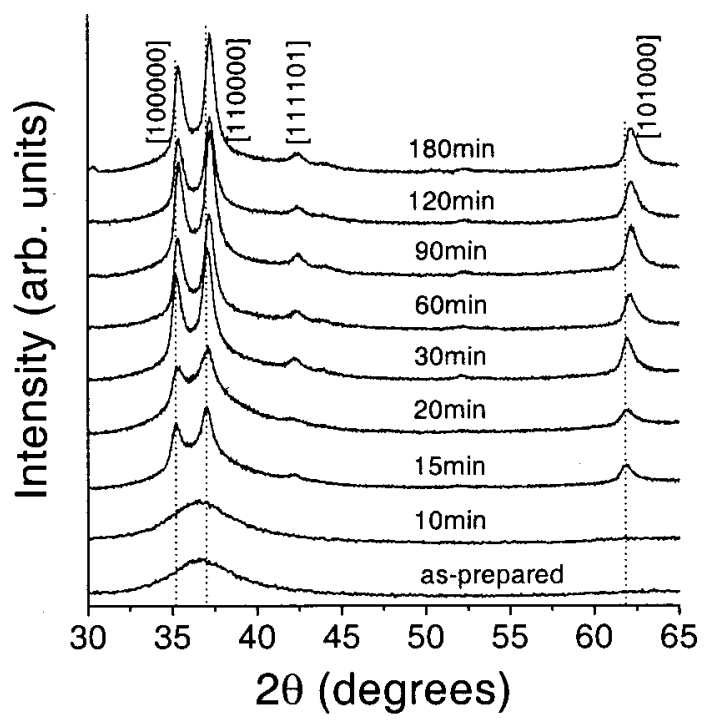

FIG. 1. XRD patterns recorded for the as-prepared $\mathrm{Zr}_{65} \mathrm{Al}_{7.5} \mathrm{Ni}_{10} \mathrm{Cu}_{7.5} \mathrm{Ag}_{10}$ metallic glass and the samples annealed at $663 \mathrm{~K}$ for 10, 15, 20, 30, 60, 90, 120, and $180 \mathrm{~min}$ in a vacuum, using $\mathrm{Cu} \mathrm{K} \alpha$ radiation. 
$=44 \mathrm{~K}$. For the structural evolution, the sample was annealed at $663 \mathrm{~K}$, below $T_{x 1}$, for $5,10,15,20,30,60,90$, 120 , and $180 \mathrm{~min}$ in a vacuum of about $10^{-5} \mathrm{mbar}$. The XRD data were collected in Bragg-Brentano scattering geometry with a Philips PW 1820/3711 diffractometer using $\mathrm{Cu}$ $\mathrm{K} \alpha$ radiation. The data were collected in the $2 \theta$ range of $20^{\circ}-100^{\circ}$ with a step length of $0.02^{\circ}$ and a counting time of $30 \mathrm{~s}$ per step. TEM measurements were carried out with a Philips CM 200 microscope operated at $200 \mathrm{kV}$. Local chemical composition was determined using EDX analysis on an area about $3 \mathrm{~nm}$ in diameter.

Figure 1 shows the XRD patterns recorded for the asprepared $\mathrm{Zr}_{65} \mathrm{Al}_{7.5} \mathrm{Ni}_{10} \mathrm{Cu}_{7.5} \mathrm{Ag}_{10}$ metallic glass and the samples annealed at $663 \mathrm{~K}$ for $10,15,20,30,60,90,120$, and $180 \mathrm{~min}$. It is clear that after $10 \mathrm{~min}$, the sample is still amorphous while the XRD pattern recorded after $15 \mathrm{~min}$ shows some broad diffraction peaks. A primitive icosahedral structure was found to be the most promising indexing scheme. ${ }^{13,14}$ The icosahedral Miller indices are generated by cyclic permutations of $\left(q_{x}, q_{y}, q_{z}\right)=( \pm 1, \pm \delta, 0)$. Six independent vectors are expressed by: $q_{1}=(1, \delta, 0) ; q_{2}=(1$, $-\delta, 0) ; q_{3}=(0,1, \delta) ; q_{4}=(0,1,-\delta) ; \quad q_{5}=(\delta, 0,1) ;$ and $q_{6}$ $=(-\delta, 0,1)$, where $\delta$ is the golden mean, 1.618. As an example, the (110000) peak is found at $q=Q_{0}\left(q_{1}+q_{2}\right)$ $=(2,0,0)$, and $Q_{0}=2 \pi / a$, where $a$ is the quasilattice constant. The average quasilattice constant is found to be $a$ $=4.843(5) \AA$. The peak $\left(2 \theta \approx 35.3^{\circ}, q \approx 2.5 \AA^{-1}\right)$ is a choice for the basic $(100000)$ reciprocal lattice vector. With increasing time, the quasicrystalline diffraction peaks remain and no new diffraction peaks were detected in the sample annealed for $180 \mathrm{~min}$. By closely examining the XRD patterns recorded, we found that diffraction peaks shift to high angles with annealing time. Diffraction peak positions and widths were estimated from fitting the XRD patterns taking into account the remaining amorphous phase. The corresponding quasilattice constant deduced from the three strongest peaks as a function of the annealing time are shown in Fig. 2. The quasilattice constant decreases with annealing time and remains almost unchanged after $90 \mathrm{~min}$. To confirm the peak position shift in the annealed samples, we repeated the XRD measurements and found the same peak shifts. The $2 \theta$-zero and strain effects on the peak position shift were also considered and found that they are negligible. Furthermore, we perform nanobeam ( $3 \mathrm{~nm}$ in diameter) EDX measurements on two samples annealed for 10 and $60 \mathrm{~min}$, as summarized in Tables I and II. Note that less than about 3\% of the quasicrystalline phase in the sample annealed for $10 \mathrm{~min}$ is hardly detected by XRD. It is found that in the sample annealed for 10 min by comparing with the remaining amorphous phase, the average zirconium content in the quasicrystalline phase is low while the average silver content is high within experimental uncertainty. These discrepancies become much larger in the sample annealed for $60 \mathrm{~min}$. Other elements remain the same in the quasicrystalline and the remaining amorphous matrix within experimental uncertainty. Note that if one considers some matrix material above and below the quasicrystalline particles, the zirconium content in quasicrystalline particles is still lower than that in the residual amorphous matrix. The results obtained here clearly reveal that the amorphous-to-quasicrystalline phase transforDownloaded 05 Mar 2010 to 192.38.67.112. Redistribution subject

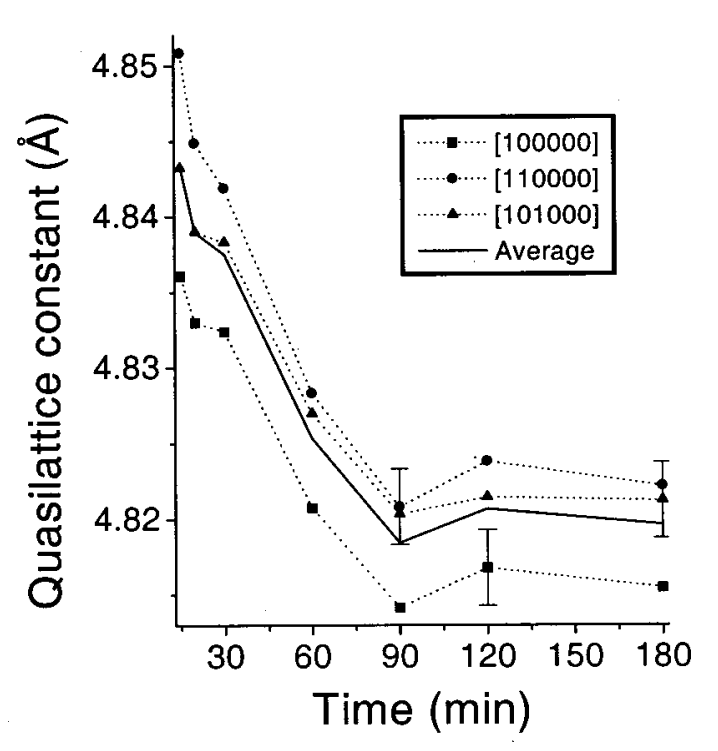

FIG. 2. Quasilattice constant of the icosahedral quasicrystalline phase as a function of the annealing time.

mation in the $\mathrm{Zr}_{65} \mathrm{Al}_{7.5} \mathrm{Ni}_{10} \mathrm{Cu}_{7.5} \mathrm{Ag}_{10}$ metallic glass involves in redistribution of zirconium and silver atoms. It should be noted that the sample used in Ref. 10 was annealed only for $1 \mathrm{~min}$ at $705 \mathrm{~K}$ while the samples studied here and in Ref. 14 were annealed for longer times. This discrepancy might indicate that the atomic redistribution effect is small, even negligible, during faster phase transformation at high temperatures while it can be detectable during slower phase transformation at low temperatures. Furthermore, to estimate the grain size of the quasicrystalline phase in the annealed samples, 60 and 101 particles, from TEM micrographs, were counted for samples annealed for $10 \mathrm{~min}$ and $60 \mathrm{~min}$, respectively. The grain size of the quasicrystalline phase is ranging of $5-50 \mathrm{~nm}$ with average grain sizes of $9.2 \mathrm{~nm}$ and $15.9 \mathrm{~nm}$ for the samples annealed for $10 \mathrm{~min}$ and $60 \mathrm{~min}$, respectively. The reduction of quasilattice constant may be caused by (1) the decrease of zirconium content in the particles because zirconium atom has the largest atomic size in the alloy, and/or (2) a grain size effect on quasilattice constant of the

TABLE I. Analytical compositions in quasicrystalline particles and the remaining amorphous phase in the $\mathrm{Zr}_{65} \mathrm{Al}_{7.5} \mathrm{Ni}_{10} \mathrm{Cu}_{7.5} \mathrm{Ag}_{10}$ sample annealed at $663 \mathrm{~K}$ for $10 \mathrm{~min}$ in a vacuum.

\begin{tabular}{lccccc}
\hline \hline & $\mathrm{Al}$ & $\mathrm{Ni}$ & $\mathrm{Cu}$ & $\mathrm{Zr}$ & $\mathrm{Ag}$ \\
\hline Quasicrystalline & $3.9 \pm 1.1$ & $9.8 \pm 0.7$ & $12.3 \pm 0.6$ & $59.7 \pm 0.3$ & $14.2 \pm 0.8$ \\
particle & & & & & \\
& $4.1 \pm 1.1$ & $9.4 \pm 0.7$ & $10.2 \pm 0.7$ & $63.5 \pm 0.3$ & $12.8 \pm 0.9$ \\
& $4.3 \pm 1.0$ & $9.6 \pm 0.6$ & $10.0 \pm 0.6$ & $64.5 \pm 0.3$ & $11.5 \pm 0.9$ \\
& $4.4 \pm 1.1$ & $9.7 \pm 0.6$ & $10.4 \pm 0.6$ & $60.6 \pm 0.3$ & $14.9 \pm 0.8$ \\
& $4.1 \pm 1.0$ & $9.8 \pm 0.6$ & $10.0 \pm 0.6$ & $62.0 \pm 0.3$ & $14.1 \pm 0.8$ \\
Average & $4.2 \pm 1.1$ & $9.7 \pm 0.6$ & $10.6 \pm 0.6$ & $62.1 \pm 0.3$ & $13.5 \pm 0.8$ \\
Amorphous & $4.4 \pm 1.2$ & $10.4 \pm 0.7$ & $11.4 \pm 0.7$ & $64.3 \pm 0.4$ & $9.3 \pm 1.2$ \\
matrix & & & & & \\
& $5.1 \pm 1.0$ & $10.0 \pm 0.6$ & $10.5 \pm 0.6$ & $65.5 \pm 0.3$ & $9.0 \pm 1.0$ \\
& $5.3 \pm 0.9$ & $10.6 \pm 0.6$ & $10.8 \pm 0.6$ & $63.8 \pm 0.3$ & $9.5 \pm 0.9$ \\
& $4.4 \pm 1.1$ & $10.1 \pm 0.7$ & $10.5 \pm 0.7$ & $65.8 \pm 0.3$ & $9.3 \pm 1.1$ \\
Average & $4.6 \pm 1.0$ & $10.7 \pm 0.6$ & $10.3 \pm 0.6$ & $65.0 \pm 0.3$ & $9.3 \pm 1.0$ \\
\hline \hline & $4.8 \pm 1.0$ & $10.4 \pm 0.6$ & $10.7 \pm 0.6$ & $64.9 \pm 0.3$ & $9.3 \pm 1.0$ \\
\hline Al & & & & & \\
& &
\end{tabular}


TABLE II. Analytical compositions in quasicrystalline particles and the remaining amorphous phase in the $\mathrm{Zr}_{65} \mathrm{Al}_{7.5} \mathrm{Ni}_{10} \mathrm{Cu}_{7.5} \mathrm{Ag}_{10}$ sample annealed at $663 \mathrm{~K}$ for $60 \mathrm{~min}$ in a vacuum.

\begin{tabular}{lccccc}
\hline \hline & $\mathrm{Al}$ & $\mathrm{Ni}$ & $\mathrm{Cu}$ & $\mathrm{Zr}$ & $\mathrm{Ag}$ \\
\hline $\begin{array}{l}\text { Quasicrystalline } \\
\text { particle }\end{array}$ & $3.6 \pm 1.2$ & $6.6 \pm 1.5$ & $8.3 \pm 1.5$ & $61.4 \pm 0.3$ & $20.1 \pm 0.5$ \\
& & & & & \\
& $3.6 \pm 1.2$ & $6.7 \pm 1.5$ & $7.5 \pm 1.5$ & $56.4 \pm 0.3$ & $25.9 \pm 0.6$ \\
& $3.7 \pm 1.2$ & $7.4 \pm 1.5$ & $9.1 \pm 1.5$ & $61.5 \pm 0.2$ & $18.4 \pm 0.6$ \\
& $4.1 \pm 1.2$ & $7.4 \pm 1.5$ & $9.3 \pm 1.5$ & $60.0 \pm 0.2$ & $19.2 \pm 0.5$ \\
& $4.1 \pm 1.2$ & $7.9 \pm 1.5$ & $8.6 \pm 1.5$ & $58.8 \pm 0.2$ & $20.6 \pm 0.6$ \\
& $3.3 \pm 1.3$ & $5.9 \pm 1.5$ & $7.5 \pm 1.5$ & $51.7 \pm 0.3$ & $31.6 \pm 0.6$ \\
& $3.9 \pm 1.3$ & $6.6 \pm 1.5$ & $7.8 \pm 1.5$ & $61.2 \pm 0.3$ & $20.4 \pm 0.6$ \\
& $4.2 \pm 1.2$ & $8.0 \pm 1.5$ & $10.1 \pm 1.5$ & $60.0 \pm 0.3$ & $17.6 \pm 0.6$ \\
Average & $3.5 \pm 1.3$ & $6.1 \pm 1.5$ & $7.5 \pm 1.5$ & $55.5 \pm 0.3$ & $27.4 \pm 0.5$ \\
Amorphous & $4.1 \pm 1.3$ & $7.1 \pm 1.5$ & $8.1 \pm 1.5$ & $57.2 \pm 0.3$ & $23.5 \pm 0.6$ \\
matrix & $3.8 \pm 1.3$ & $7.0 \pm 1.5$ & $8.4 \pm 1.5$ & $58.4 \pm 0.3$ & $22.5 \pm 0.6$ \\
& $5.0 \pm 1.2$ & $9.1 \pm 1.4$ & $9.4 \pm 1.5$ & $68.4 \pm 0.3$ & $8.1 \pm 1.3$ \\
& & & & & \\
& $4.9 \pm 1.2$ & $8.6 \pm 1.4$ & $8.5 \pm 1.5$ & $70.3 \pm 0.2$ & $7.6 \pm 1.3$ \\
& $4.8 \pm 1.2$ & $8.4 \pm 1.4$ & $8.9 \pm 1.5$ & $69.9 \pm 0.3$ & $8.1 \pm 1.3$ \\
& $4.9 \pm 1.2$ & $7.3 \pm 1.4$ & $8.5 \pm 1.5$ & $69.9 \pm 0.3$ & $9.4 \pm 1.2$ \\
Average & $5.2 \pm 1.2$ & $7.7 \pm 1.4$ & $9.0 \pm 1.5$ & $67.9 \pm 0.3$ & $10.2 \pm 1.2$ \\
\hline \hline & $4.7 \pm 1.3$ & $10.4 \pm 1.4$ & $9.2 \pm 1.5$ & $67.3 \pm 0.3$ & $8.4 \pm 1.3$ \\
& $4.0 \pm 1.3$ & $5.9 \pm 1.4$ & $7.1 \pm 1.5$ & $69.9 \pm 0.3$ & $13.0 \pm 1.2$ \\
& $5.7 \pm 1.2$ & $8.2 \pm 1.4$ & $9.2 \pm 1.5$ & $67.3 \pm 0.3$ & $9.5 \pm 1.2$ \\
& $5.4 \pm 1.2$ & $9.1 \pm 1.4$ & $9.3 \pm 1.5$ & $68.1 \pm 0.3$ & $8.1 \pm 1.3$ \\
& $5.3 \pm 1.2$ & $8.7 \pm 1.4$ & $9.0 \pm 1.5$ & $68.2 \pm 0.3$ & $8.7 \pm 1.2$ \\
& $5.9 \pm 1.2$ & $7.2 \pm 1.4$ & $8.7 \pm 1.5$ & $69.5 \pm 0.2$ & $8.7 \pm 1.3$ \\
& $5.1 \pm 1.3$ & $8.2 \pm 1.4$ & $8.8 \pm 1.5$ & $68.8 \pm 0.3$ & $9.1 \pm 1.3$ \\
\hline & & & & &
\end{tabular}

quasicrystalline phase because the size dependence of lattice parameter in nanocrystals has been reported in the literature due to a large fraction of surface atoms. ${ }^{18,19}$ Why should the zirconium content in quasicrystals decrease with the annealing time? The quasicrystalline phase could be formed in a range of compositions. During annealing, atoms diffuse in and out of quasicrystals so that the zirconium content in quasicrystals could vary with annealing time. The experimental results obtained here will trigger further investigation on the relationship of composition, quasilattice constant, and grain size of the quasicrystalline phase.

In conclusion, the amorphous-to-quasicrystalline phase transformation in the $\mathrm{Zr}_{65} \mathrm{Al}_{7.5} \mathrm{Ni}_{10} \mathrm{Cu}_{7.5} \mathrm{Ag}_{10}$ metallic glass has been investigated by monitoring the quasilattice constant and the composition of quasicrystalline particles in the samples annealed at $663 \mathrm{~K}$ for various times. We found that quasilattice constant decreases with annealing time and saturates after $90 \mathrm{~min}$ while the zirconium content in quasicrystalline particles decreases whereas silver content increases. The results suggest a nonpolymorphous reaction for the amorphous-to-quasicrystalline phase transformation in the $\mathrm{Zr}_{65} \mathrm{Al}_{7.5} \mathrm{Ni}_{10} \mathrm{Cu}_{7.5} \mathrm{Ag}_{10}$ metallic glass. This is in consistent with the conclusion derived in the literature. ${ }^{11,14}$

Financial support from the Danish Technical Research Council and the Danish Natural Sciences Research Council is gratefully acknowledged.

${ }^{1}$ U. Köster, J. Meinhardt, S. Roos, and H. Liebertz, Appl. Phys. Lett. 69, 179 (1996); U. Köster, J. Meinhardt, S. Roos, and A. Rudiger, Mater. Sci. Forum 225, 311 (1996).

${ }^{2}$ U. Köster, J. Meinhardt, S. Roos, and R. Busch, Mater. Sci. Eng., A 226, 995 (1997); D. Zander, R. Janlewing, A. Rudiger, and U. Köster, Mater. Sci. Forum 307, 25 (1999).

${ }^{3}$ J. Eckert, N. Mattern, M. Zinkevitch, and M. Seidel, Mater. Trans., JIM 39, 623 (1998).

${ }^{4}$ L. Q. Xing, J. Eckert, W. Loser, and L. Schultz, Appl. Phys. Lett. 73, 2110 (1998); ibid. 74, 664 (1999).

${ }^{5}$ M. W. Chen, T. Zhang, A. Inoue, A. Sakai, and T. Sakural, Appl. Phys. Lett. 75, 1697 (1999).

${ }^{6}$ A. Inoue, T. Zhang, J. Saida, M. Matsushita, M. W. Chen, and T. Sakural, Mater. Trans., JIM 40, 1137 (1999); ibid. 40, 1181 (1999).

${ }^{7}$ J. Saida, M. Matsushita, T. Zhang, A. Inoue, M. W. Chen, and T. Sakural, Appl. Phys. Lett. 75, 3497 (1999); J. Saida, M. Matsushita, and A. Inoue, ibid. 77, 73 (2000); J. Appl. Phys. 88, 6081 (2000); J. Saida, M. Matsushita, C. Li, and A. Inoue, Appl. Phys. Lett. 76, 3558 (2000).

${ }^{8}$ B. S. Murty, D. H. Ping, and K. Hono, Appl. Phys. Lett. 77, 1102 (2000); B. S. Murty, D. H. Ping, K. Hono, and A. Inoue, ibid. 76, 55 (2000); Scr. Mater. 43, 103 (2000).

${ }^{9}$ S. Yi and D. H. Kim, J. Mater. Res. 15, 892 (2000).

${ }^{10}$ A. Inoue, T. Zhang, J. Saida, and M. Matsushita, Mater. Trans., JIM 41, 1511 (2000); A. Inoue, T. Zhang, M. W. Chen, T. Sakurai, J. Saida, and M. Matsushita, Appl. Phys. Lett. 76, 967 (2000).

${ }^{11}$ J. K. Lee, G. Choi, D. H. Kim, and W. T. Kim, Appl. Phys. Lett. 77, 978 (2000).

${ }^{12}$ U. Kuhn, J. Eckert, N. Mattern, and L. Schultz, Appl. Phys. Lett. 77, 3176 (2000).

${ }^{13}$ N. Wanderka, M.-P. Macht, M. Seidel, S. Mechler, K. Ståhl, and J. Z. Jiang, Appl. Phys. Lett. 77, 3935 (2000).

${ }^{14}$ J. Z. Jiang, Y. X. Zhuang, H. Rasmussen, J. Saida, and A. Inoue, Phys. Rev. B 64, 094208 (2001).

${ }^{15}$ J. Z. Jiang, K. Saksl, H. K. Rasmussen, T. Watanuki, N. Ishimatu, and O. Shimomara, Appl. Phys. Lett. 79, 1112 (2001).

${ }^{16}$ J. Z. Jiang, K. Saksl, J. Saida, A. Inoue, H. Franz, K. Messel, and C. Lathe, Appl. Phys. Lett. 80, 781 (2002).

${ }^{17}$ D. V. Louzguine and A. Inoue, Appl. Phys. Lett. 78, 1841 (2001).

${ }^{18}$ J. Woltersdorf, A. S. Nepijko, and E. Pippel, Surf. Sci. 106, 64 (1981).

${ }^{19}$ C. Solliard and M. Flueli, Surf. Sci. 156, 487 (1985). 